\title{
La Universidad Simón Bolívar, en el trasegar de la investigación, medición y visibilidad
}

Ferney Asdrúbal Rodríguez Serpa

Abogado, Sociólogo, Mg en Derecho Procesal. Doctorante en Filosofía con orientación en Ciencias Políticas de la Universidad Autónoma de Nuevo León. Monterrey-México. Docente-Investigador de pregrado y postgrado. Integrante de la Red

Iberoamericana de iusticia alternativa, transicional y restaurativa. Red de Justicia ATR. Editor Revista Justicia

Los cambios trascendentales que la Universidad Simón Bolívar han tenido en las últimas décadas en materia de ciencia, tecnología e innovación, no son del "aquí y ahora"; son consecuencia del esfuerzo institucional por comprender el discurso global y complejo que dinamiza la investigación científica del más alto nivel. De ahí que los frutos de hoy son efecto de la comprensión de dicha dinámica. Dinámica que en esencia, tiene como protagonistas de la historia institucional a sus profesores investigadores.

Hoy, tales esfuerzos no son estériles como ocurrió en el pasado, especialmente en los incipientes procesos de ciencias y tecnologías de los años 80 y 90 donde no cabe duda fuimos pioneros en la región Caribe, en cabeza del maestro José Consuegra Higgins, Aquiles Escalante, Fernando Piñeres, Alberto Reales Utria, entre otros científicos sociales de aquella época y que son la génesis de lo que es la investigación científica en esta Casa de Estudio. Adicionalmente, es ineludible destacar la visibilidad de aquella producción científica a través de la Revista Desarrollo Indoamericano.

Ahora bien, cuando hablé de aquella esterilidad de los esfuerzos suele sonar fuerte, no obstante, era real, mas no era un malestar solo de nuestra universidad, sino de todas las instituciones de educación superior públicas y privadas de Colombia, en síntesis, era un problema paupérrimo del sistema de ciencia, tecnología e innovación de Colombia en aquellos tiempos bajo la dirección del aquel entonces Instituto Colombiano para el Desarrollo de la Ciencia y la Tecnología.
Editorial

Copyright $\odot 2018$ Rodríguez 
La fortuna del presente, supera la esterilidad del pasado, y la razón estriba en la existencia de disímiles indicadores que hacen posible que la producción científica sea medible, y en efecto, posibilitar las comparaciones de crecimiento y estancamiento entre las instituciones pertenecientes al sistema de ciencias y tecnologías, las cuales seguramente son todas, pues en suma es lo que permite medir la existencia de las instituciones en todos sus niveles. En este sentido, la medición de los centros de investigación, grupos de investigación, los investigadores y las revistas científicas han posibilitado distinguir las fortalezas y debilidades de estos, y han permitido generar planes de mejora al interior de los mismos.

En esta nueva lógica, no obstante se hace un homenaje a algunos ilustre investigadores del pasado que a la postre han vivido para recoger los frutos del presente, es decir, de aquellos grandes investigadores que tienen la fortuna de que sus investigaciones sean medidas a la luz de las nuevas políticas del Departamento Administrativo de Ciencia, Tecnología e Innovación Francisco José de Caldas, Colciencias; con ello destaco la cualificación de investigadores como Jairo Solano, Raimundo Caviedes, Jorge Bolívar Berdugo, Gustavo Aroca, entre otros, que de antemano les extiendo mis excusas por omitirlos.

De otro lado, quisiera destacar nuestro sistema de publicaciones que cada vez es más sistemático, riguroso, selectivo y sofisticado, y ha permitido visibilizar no solo la producción científica endógena, sino aquella que en alianza con otras instituciones a través de redes de conocimiento científico a nivel nacional e internacional se han gestado.

En el caso específico de las revistas científicas institucionales, se desea destacar en esta ocasión, la posibilidad de vislumbrar desde el análisis de producción de los últimos tres años fuertes tendencias en el devenir de la producción científica. Para este análisis se destacan las tendencias marcadas por las Revistas Educación y Humanismo, Psicogente, Desarrollo Gerencial y Justicia.

En cuanto a la primera, en Educación y Humanismo resultan relevantes los estudios sobre "Revisión de las evaluaciones adaptativas computarizadas (CAT)" (2014, López, Sanmartín \& Méndez), el trabajo de Villalba (2016), sobre "La convivencia escolar en positivo", Ibagón, (2015) sobre "La educación, un derecho que cuesta: dimensión fiscal y su relación con la política educativa en América Latina", Orostegui, Lastre, \& Gaviria (2015) "La ética del profesor religada a la formación en valores del estudiante. Mirada teórica", Castillo \& Morales (2013) "Los estudios de género a las nuevas masculinidades y/o los movimientos de padres por la custodia compartida de sus hijos e hijas", Silvera, (2016) "La evaluación y su 
incidencia en la deserción escolar:¿ Falla de un sistema, de las instituciones educativas, del docente o del estudiante?" y Rodríguez, (2017) "Currículum, educación y cultura en la formación docente del siglo XXI desde la complejidad"; del mismo modo se destacan en la Revista Psicogente los trabajos de Enríquez, Fajardo, y Garzón (2015), sobre "Una revisión general a los hábitos y técnicas de estudio en el ámbito universitario" y el estudio sobre "Creencias irracionales, síndrome de Burnout y adicción al trabajo en las organizaciones" (2016, Polo, Santiago, Navarro \& Alí).

Por su parte en la Revista Desarrollo Gerencial se destacan las investigaciones sobre las empresas familiares, de ahí las investigaciones sobre "Protocolos: un instrumento para mediar conflictos en empresas familiares" (2015, Vanoni \& Pérez) y la investigación "Autotomía caudal como estrategia gerencial para el cambio organizacional en empresas familiares" (2015, El Kadi, Pelekais, Robles \& Leal). Y finalmente, en cuanto a la Revista Justicia, se subrayan los estudios sobre "La verdad y la justicia frente a la prueba en el proceso penal" (2015, Vicuña \& Castillo) y el trabajo de Mosquera (2015), sobre "Derechos de las minorías sexuales: retos contemporáneos de la resocialización".

\section{REFERENCIAS}

Castillo, J. \& Morales, H. (2013). Los estudios de género a las nuevas masculinidades $\mathrm{y} / \mathrm{o}$ los movimientos de padres por la custodia compartida de sus hijos e hijas. Revista Educación y Humanismo, 15(24), 108-121.

El Kadi, O., Pelekais, C., Robles, M. \& Leal, M. (2015). Autotomía caudal como estrategia gerencial para el cambio organizacional en empresas familiares. Desarrollo Gerencial. Revista de la Facultad de Ciencias Económicas, Administrativas y Contables, 7(1), 68-84.

Enríquez, M., Fajardo, M. \& Garzón, F. (2015). Una revisión general a los hábitos y técnicas de estudio en el ámbito universitario. Psicogente, 18(33), 166-187. http://doi.org/10.17081/psico.18.33.64

Ibagón, N. (2015). La educación, un derecho que cuesta: dimensión fiscal y su relación con la política educativa en América Latina. Revista Educación y Humanismo, 17(28), 29-37. DOI: http://dx.doi.org/10.17081/eduhum.17.28.1164

López, R., Sanmartín, P. \& Méndez, F. (2014). Revisión de las evaluaciones adaptativas computarizadas (CAT). Revista Educación y Humanismo, 16(26), 27-40.

Mosquera Rentería, J. (2015). Derechos de las minorías sexuales: retos contemporáneos de la resocialización. Justicia, 28, 121-138. http://dx.doi.org/10.17081/just.20.28.1044 
Orostegui, M., Lastre, G. \& Gaviria, G. (2015). La ética del profesor religada a la formación en valores del estudiante. Mirada teórica. Revista Educación y Humanismo, 17(29), 272-285. Doi: http://dx.doi.org/10.17081/eduhum.17.29.1257

Polo, J. D., Santiago, V., Navarro, M. C. \& Alí, A. (2016). Creencias irracionales, síndrome de Burnout y adicción al trabajo en las organizaciones. Psicogente, 19(35), 148-160. http://doi.org/10.17081/psico.19.35.1215

Rodríguez, M. (2017). Currículum, educación y cultura en la formación docente del siglo XXI desde la complejidad. Revista Educación y Humanismo, 19(33), 425-440. DOI: http://dx.doi.org/10.17081/eduhum.19.33.2654

Silvera, L. (2016). La evaluación y su incidencia en la deserción escolar: ¿Falla de un sistema, de las instituciones educativas, del docente o del estudiante? Revista Educación y Humanismo, 18(31), 313-325. DOI: http://dx.doi.org/10.17081/eduhum.18.31.1381

Vanoni, G. \& Pérez, M. (2015). Protocolos: un instrumento para mediar conflictos en empresas familiares. Desarrollo Gerencial. Revista de la Facultad de Ciencias Económicas, Administrativas y Contables, 7(2), 81-99.http://dx.doi.org/10.17081/dege.7.2.1182

Vicuña, M. \& Castillo, S. (2015). La verdad y la justicia frente a la prueba en el proceso penal. Justicia, 27, 118-134. http://doi.org/10.17081/ just.3.27.323

Villalba, J. (2016). La convivencia escolar en positivo. Revista Educación y Humanismo, 18(30),92-106.http://dx.doi.org/10.17081/eduhum.18.30.1324 